\title{
Ultrasound cardiac output monitoring in mechanically ventilated children
}

\author{
Jiri Fremuth, Jiri Kobr, Lumir Sasek, Katerina Pizingerova, Jana Zamboryova, Josef Sykora
}

\begin{abstract}
Aim. To non-invasively identify the hemodynamic changes in critically ill children during the first $48 \mathrm{~h}$ following initiation of mechanical ventilation by the ultrasound cardiac output monitor (USCOM) method and compare the data in children with pulmonary and non-pulmonary pathology.

Materials and Methods. This was a prospective observational study to evaluate the influence of mechanical ventilation on hemodynamic changes and to describe hemodynamic profiles of mechanically ventilated children. A total of 56 children with respiratory failure were included in the present study. Ventilated patients are divided into two groups. Group $A(n=36)$ includes patients with pulmonary pathology. Group B $(n=20)$ consists of patients with extra pulmonary etiology of respiratory failure. Hemodynamic parameters (cardiac index and systemic vascular resistance index) were evaluated using ultrasound cardiac output monitoring (USCOM 1A) immediately following initiation of mechanical ventilation and again at 6, 12, and $48 \mathrm{~h}$. Pharmacological circulatory support (inotropes, vasopressors, levosimendan and phosphodiesterase III inhibitors) was individually and continuously modified based on real-time hemodynamic parameters and optimal fluid balance.

Results. No significant differences in hemodynamic profiles were found between Group A and Group B.

Conclusion. The protective strategy of mechanical ventilation was not associated with significant differences in hemodynamic profiles between children ventilated for pulmonary and non-pulmonary pathologies.

Clinical Significance. Hemodynamically unstable children ventilated for pulmonary pathology with the protective strategy of mechanical ventilation had a greater requirement for inotropic and combined inotropic and vasoactive circulatory support than children ventilated for non-pulmonary causes of respiratory failure.
\end{abstract}

Key words: hemodynamics, ultrasound cardiac output monitor, mechanical ventilation, children, case-control study

Received: March 24, 2020; Revised: September 15, 2020; Accepted: October 6, 2020; Available online: October 21,2020 https://doi.org/10.5507/bp.2020.048

(c) 2021 The Authors; https://creativecommons.org/licenses/by/4.0/

Department of Pediatrics - PICU, Faculty of Medicine in Pilsen, Charles University in Prague, Czech Republic Corresponding author: Jiri Kobr, e-mail:Jikobr93@gmail.com

\section{INTRODUCTION}

Circulatory failure in critically ill children is most often caused by a low circulatory volume and low myocardial contractility or a decrease in systemic vascular resistance. Treatment aims to optimize oxygen delivery to peripheral tissues according to the current needs of the child by supporting blood circulation and ventilation. Cardiac output is determined by the heart rate and stroke volume, and blood pressure by cardiac output and systemic vascular resistance. Current and reliable hemodynamic evaluation is necessary for effective treatment, and hemodynamic monitoring helps physicians to identify early pathophysiological changes and choose an appropriate treatment strategy ${ }^{1,2}$. Published studies have clearly shown that a clinical estimation of hemodynamic parameters, such as cardiac index and systemic vascular resistance, does not correspond to invasively measured results in critically ill pediatric or adult patients $\mathrm{s}^{3,4}$. The interval from first presentation to cardiac output measurement using invasive techniques typically exceeds the 60-minute period recommended by the American College of Critical Care Medicine guidelines for fluid resuscitation and selection of first- and second-line vasoactive and inotropic drugs ${ }^{1}$.
It should be noted that previously published studies have only documented changes in hemodynamics in septic children $^{5}$, and the initial treatment strategy for critically ill, hemodynamically unstable pediatric patients is often based on fluid administration ${ }^{6}$. Following initial resuscitation of fluid-responsive pediatric patients, the fluid, vasoactive, and inotropic therapies should be selected based on the profile obtained from hemodynamic monitoring.

From a clinical point of view, there has been increasing interest in, and preference for, the use of semi- or non-invasive techniques to measure cardiac output; and an ultrasound cardiac output monitor (USCOM 1A) has recently become available for use in clinical practice. Conventional mechanical ventilation with permanent positive pressure induces cardiopulmonary interactions and reduces myocardial performance ${ }^{7,8}$; however, clinical studies considering these interactions are almost nonexistent in the pediatric population, even though understanding these interaction patterns is essential for the treatment of critically ill children. Patients ventilated for pulmonary pathology often require higher inspiratory pressures to achieve the desired tidal volume, and cardiopulmonary interactions in these groups of children are more pronounced ${ }^{9,10}$. 
Doppler ultrasound-based methods have become widely popular and have expanded into the intensive care setting. In general, the main interest in echocardiography is that it can be used not only for the measurement of cardiac output ( $\mathrm{CO})$ but also for the additional assessment of cardiac anatomy and function. The global myocardial performance is evaluated by transthoracic functional echography using the Tei-index calculation ${ }^{11,12}$; however, echocardiography instruments and expertise may not be readily available in most institutions since this remains the domain of cardiologists. Conversely, the cardiology erudition of the operator is not a necessary condition for accurate measurement of hemodynamics using the USCOM method, and it is for this practical reason that this methodology has been a preferred method in our settings in recent years.

The need for increased understanding of basic pathophysiological mechanisms led to the execution of the current study. Here, we non-invasively identify the hemodynamic changes in critically ill children during the first $48 \mathrm{~h}$ following initiation of mechanical ventilation by the USCOM method and compare data in children with pulmonary and non-pulmonary pathologies.

\section{MATERIALS AND METHODS}

This was a prospective, observational study of hemodynamic changes in mechanically ventilated children. The local ethical committee at our institution approved the study. The investigator explained the purpose of the study and written consent was obtained from an authorized representative.

\section{Study population}

The study population consisted of consecutive pediatric hemodynamically unstable patients with respiratory failure and the requirement for mechanical ventilation. A total of 56 children, in the age range from 1 month to 17 years old, were enrolled in the present study. The patients were divided into two groups according to primary pathology; group A $(n=36)$ included children with pulmonary pathology and the group $B(n=20)$ included children ventilated for non-pulmonary pathology. Children in group A were admitted for the following diagnoses: pneumonia (21 patients), bronchiolitis (8), aspiration of stomach contents (4), near-drowning (2), and asthmatic condition (1). Children in group B were admitted for the following diagnoses: severe sepsis ( 5 patients), epileptic status (5), purulent meningitis (4), extensive abdominal surgery (4), brain edema (1), and myelitis (1).

\section{Methods}

All hemodynamically unstable children included in the present study underwent standard monitoring of vital signs (ECG, invasive arterial blood pressure, central venous pressure, one-hour diuresis) and were examined by transthoracic echocardiography (TTE) to exclude structural defects of the heart. The hemodynamic profile evaluation was performed using an ultrasound cardiac output monitor (USCOM 1A, Sydney, Australia), which is a noninvasive and accurate device with which to evaluate cardiac flow via continuous-wave Doppler echocardiography using a transcutaneous probe $(2.2 \mathrm{MHz})$. The monitor display offers beat-to-beat pulse curves without 2D imaging, and the flow profile is obtained by placing the sonographic probe on the chest in either the left parasternal or jugular position to measure transpulmonary or transaortic blood flow, respectively. The acquired beat-to-beat pulse curves are evaluated by the software; after entering the patient's age, gender, height, weight, and systemic arterial and central venous pressures, the software calculated 20 parameters of cardiovascular function including cardiac output, stroke volume, and systemic vascular resistance. Transaortic measurements were collected and analyzed to monitor the systemic hemodynamic changes. At each designated time point, each patient underwent 3 noninvasive hemodynamic assessments within $2 \mathrm{~min}$ in the jugular position, and these results were then averaged. A single operator was selected for all patients to reduce possible inter-operator variability. All pediatric patients in the present study were ventilated in a protective mode of permanently positive pressure mechanical ventilation. To evaluate the quality of mechanical ventilation, commonly used ventilation parameters and indices were monitored. Arterial blood gases were evaluated at each non-invasive hemodynamic measurement, and the fluid balance over $24 \mathrm{~h}$ was recorded for three consecutive days. The prediction of mortality was calculated using PIM 3 scores $^{13}$.

\section{Study protocol}

USCOM was used for hemodynamic monitoring within $1 \mathrm{~h}$ of the initiation of mechanical ventilation and again at 6,12 , and $48 \mathrm{~h}$ (times $1,2,3$, and 4 , respectively). Additional measurement outside these intervals was indicated in the case of sudden changes in clinical or hemodynamic conditions. To achieve an optimal systemic perfusion, the management was adjusted based on the hemodynamic profile of the patient. Pharmacological support for blood circulation was individually and continuously modified based on real-time information of hemodynamics and fluid balance. In the case of sepsis and concomitant hypotension or dehydration, treatment was based on current guidelines ${ }^{14}$ and balanced crystalloid solution boluses of 20 to $60 \mathrm{~mL} / \mathrm{kg}$ were initiated during the first hour. In other cases, maintenance fluid therapy was initiated, and further inotropic or vasoactive therapy initiation was based on hemodynamic indices obtained by USCOM. The thresholds for the hemodynamic indices were a cardiac index $(\mathrm{CI})$ of $3.3-6.0 \mathrm{~L} / \mathrm{min} / \mathrm{m}^{2}$ and a systemic vascular resistance index (SVRI) of 900-1600 dynes $/ \mathrm{sec} / \mathrm{cm}^{5} / \mathrm{m}^{2}$. Recommended age-related blood perfusion pressures were targeted ${ }^{15}$. Dobutamine was used as an initial inotropic drug, and noradrenaline was used as an initial vasopressor. In the case of a low CI state associated with a high SVRI, a phosphodiesterase III inhibitor was used. Adrenaline was used in the case of a low CI state and the patient being unresponsive to standard fluid management and inotropic treatment. Dopamine was indicated in the case of a low CI state associated 
with bradycardia. Other treatment options of antibiotics and adjuvant therapy for each child included in the study followed local protocols.

\section{Statistical analysis}

All statistical analyses were performed using the statistical software SAS (SAS Institute Inc., Cary, NC, USA) and STATISTICA (StatSoft, Inc., Tulsa, USA). The differences between the variables in each group for a given time were analyzed using the Wilcoxon two-sample test. The changes in physiological variables over time were analyzed by means of analyses of variance (paired Wilcoxon test and Friedman ANOVA). The results were checked by variance analysis. Data are expressed as the median and interquartile range. $P<0.05$ was considered statistically significant.

\section{RESULTS}

A total of 56 eligible patients, with an average age of $7.33 \pm 6.33$ years old, were included in the present study, and 672 non-invasive hemodynamic measurements were obtained and evaluated.

The characteristics of the study population are summarized in Table 1.

Groups A and B were comparable with respect to age, gender distribution, and predicted risk of death.

The hemodynamic data for groups A and B are shown in Tables 2.

No significant differences in the measured hemodynamic parameters were found between the two groups.
Table 1. Study population.

\begin{tabular}{lccc}
\hline Parameters & Group A & Group B & $P<$ \\
\hline Number & 36 & 20 & NS \\
Age (months), mean \pm SD & $44 \pm 54$ & $58 \pm 56$ & NS \\
Boys, \% & 67 & 62 & NS \\
Calculated risk of deaths $\%$ & 10.8 & 7.1 & NS \\
$\quad$ (PIM 3 score) & & & \\
ICU deaths, n/N (\%) & $1 / 36(2.7)$ & $2 / 20(10)$ & NS \\
Hospital deaths, n/N (\%) & $2 / 36(5.5)$ & $2 / 20(10)$ & NS \\
\hline
\end{tabular}

NS - not significant

The systolic blood pressure (SBP) increased in both groups, and the systemic vascular resistance index (SVRI) increased in group B over the course of the study. No significant changes in the cardiac index (CI), stroke volume index (SVI), diastolic blood pressure (DBP), or central venous pressure (CVP) were observed within either group.

In group $A(n=36), 64 \%$ of patients required administration of inotropic support during the study. At the time of the first hemodynamic evaluation, dobutamine was initiated in $31 \%$ of patients; however, the number of patients increased during the study. In the same group, $28 \%$ of children were started on noradrenaline based on the results of the first hemodynamic evaluation, and $47 \%$ of children required vasopressor treatment. Concomitant inotropic and vasopressor treatment was required in $28 \%$ of patients within $48 \mathrm{~h}$ of ventilation initiation. Administration of dopamine, adrenaline, and phosphodiesterase III inhibitors was necessary in a small number of patients.

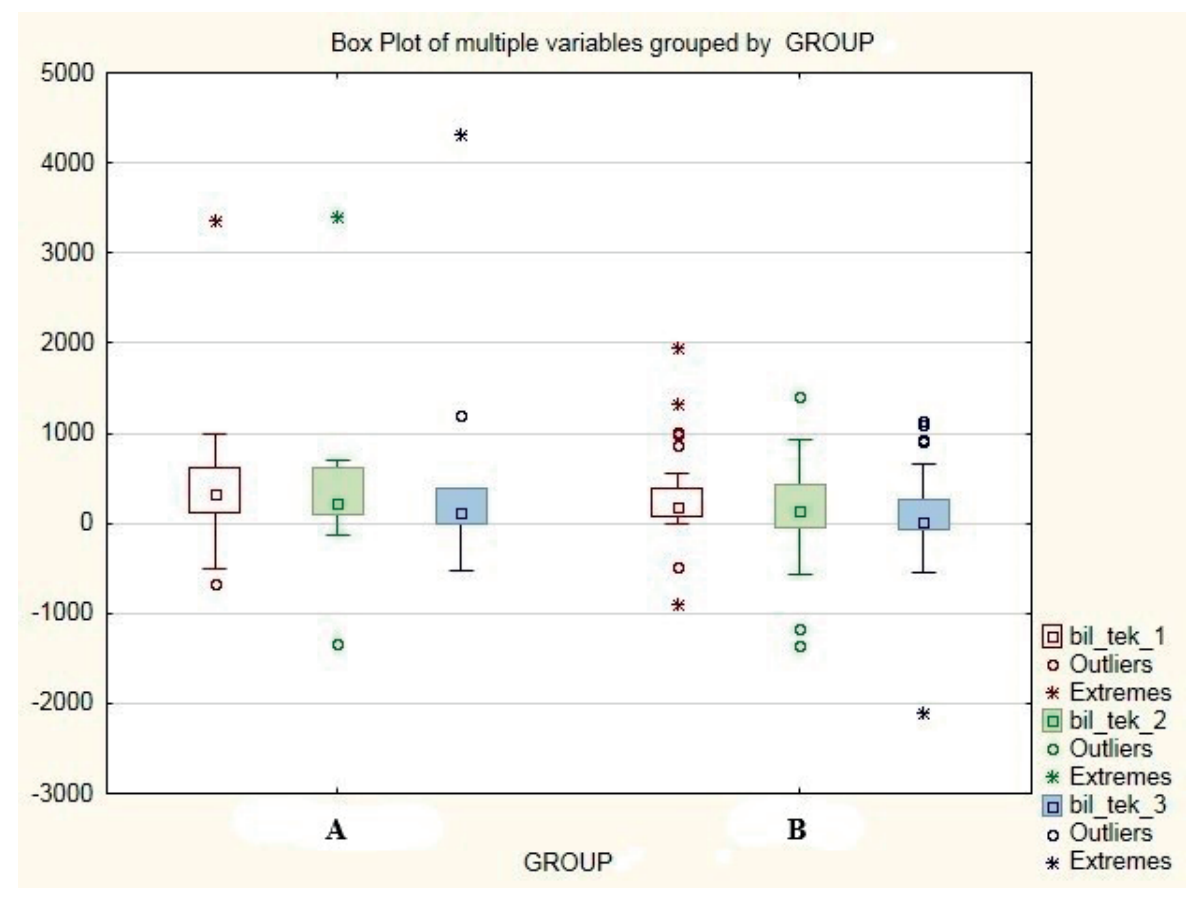

Fig. 1. Total fluid balance in the group A and B

A - Group A is patients with pulmonary pathology, B - Group B is patients with extra-pulmonary pathology 
Table 2. Hemodynamic parameters in group A and group B.

\begin{tabular}{lccccc}
\hline & Time 1 & Time 2 & Time 3 & Time 4 & $P<$ \\
\hline Group A & & & & & \\
CI & $4.40(3.30 ; 5.00)$ & $4.57(3.20 ; 4.80)$ & $4.45(3.40 ; 4.60)$ & $4.46(3.20 ; 4.80)$ & NS \\
SVRI & $1021(776 ; 1407)$ & $1047(816 ; 1437)$ & $1110(809 ; 1450)$ & $1174(856 ; 1608)$ & NS \\
SVI & $32(26 ; 39)$ & $33(27 ; 40)$ & $30(24 ; 43)$ & $31(29 ; 40)$ & NS \\
SBP & $89(78 ; 101)$ & $91(70 ; 104)$ & $97(81 ; 110)$ & $100(81 ; 118)$ & 0.014 \\
DBP & $52(38 ; 67)$ & $49(40 ; 64)$ & $51(37 ; 67)$ & $56(39 ; 71)$ & NS \\
CVP & $9(7.0 ; 11)$ & $9(7 ; 12)$ & $9(7 ; 12)$ & $9(7 ; 11)$ & NS \\
Group B & & & & $3.20(2.80 ; 4.20)$ & NS \\
CI & $4.50(3.50 ; 4.70)$ & $4.80(4.15 ; 5.15)$ & $4.00(3.70 ; 4.70)$ & $1567(1190 ; 1993)$ & 0.005 \\
SVRI & $1055(880 ; 1206)$ & $1033(877 ; 1077)$ & $1096(777 ; 1167)$ & $40(28 ; 42)$ & NS \\
SVI & $37(28 ; 45)$ & $41(30 ; 47)$ & $39(29 ; 43)$ & $108(96 ; 111)$ & 0.025 \\
SBP & $83(71 ; 99)$ & $92(85 ; 97)$ & $95(76 ; 107)$ & $58(50 ; 61)$ & NS \\
DBP & $50(36 ; 54)$ & $48(42 ; 56)$ & $48(44 ; 56)$ & $7(6 ; 9)$ & $7(6 ; 9)$ \\
CVP & $7(6 ; 9)$ & $9(6 ; 10.5)$ & & NS \\
\hline
\end{tabular}

CI - cardiac index $\left(\mathrm{L} / \mathrm{min} . / \mathrm{m}^{2}\right)$; SVRI - systemic resistance vascular index (dyne. $\left.\mathrm{sec} / \mathrm{cm}^{5} / \mathrm{m}^{2}\right)$;

SVI - stroke volume index $\left(\mathrm{mL} / \mathrm{m}^{2}\right)$; SBP - systolic blood pressure $(\mathrm{mmHg})$; DBP - diastolic blood pressure (mmHg); CVP - central venous pressure (mmHg); $P<$ values - comparison Time 4 vs. Time 1. Data are expressed as median and interquartile range.

Table 3. Ventilation indices in group A and group B.

\begin{tabular}{lccccc}
\hline & Time 1 & Time 2 & Time 3 & Time 4 & $P<$ \\
\hline Group $\mathrm{A}$ & & & & & \\
$\mathrm{VT}$ & $7.8(6.80 ; 8.50)$ & $7.70(7.00 ; 8.45)$ & $7.95(7.00 ; 8.35)$ & $8.00(7.25 ; 8.50)$ & $\mathrm{NS}$ \\
$\mathrm{PIP}$ & $28.50(23.00 ; 31.00)$ & $28.00(22.00 ; 30.50)$ & $26.50(23.00 ; 29.50)$ & $25.50(22.50 ; 28.00)$ & 0.05 \\
$\mathrm{PEEP}$ & $8.00(8.00 ; 8.00)$ & $8.00(7.00 ; 8.00)$ & $8.00(6.50 ; 9.00)$ & $14.00(12.00 ; 16.00)$ & $\mathrm{NS}$ \\
$\mathrm{OI}$ & $8.82(5.70 ; 12.00)$ & $7.25(5.33 ; 8.53)$ & $5.93(4.88 ; 9.70)$ & $5.90(4.43 ; 8.00)$ & 0.001 \\
$\mathrm{PaO}_{2} / \mathrm{FiO}_{2}$ & $170(117 ; 251)$ & $208(166 ; 266)$ & $214(165 ; 276)$ & $227(179 ; 292)$ & 0.05 \\
$\mathrm{Group} \mathrm{B}_{\mathrm{VT}}$ & & & & & \\
$\mathrm{PIP}$ & $8.00(7.30 ; 8.40)$ & $8.00(7.10 ; 8.20)$ & $8.00(7.10 ; 8.20)$ & $7.30(7.10 ; 8.00)$ & $\mathrm{NS}$ \\
$\mathrm{PEEP}$ & $20.00(19.00 ; 20.00)$ & $20.00(19.00 ; 22.00)$ & $20.00(18.00 ; 22.00)$ & $23.00(20.00 ; 24.00)$ & $\mathrm{NS}$ \\
$\mathrm{OI}$ & $6.00(6.00 ; 8.00)$ & $6.00(6.00 ; 6.00)$ & $6.00(6.00 ; 6.00)$ & $6.00(6.00 ; 6.00)$ & $\mathrm{NS}$ \\
$\mathrm{PaO}_{2} / \mathrm{FiO}_{2}$ & $3.35(2.76 ; 4.50)$ & $2.80(2.50 ; 3.74)$ & $3.63(2.76 ; 4.33)$ & $3.35(3.07 ; 4.77)$ & $\mathrm{NS}$ \\
\hline
\end{tabular}

$\mathrm{Vt}$ - tidal volume $(\mathrm{mL} / \mathrm{kg})$; PIP - peak inspiratory pressure $\left(\mathrm{cm}_{2} \mathrm{O}\right)$; $\mathrm{PEEP}$ - positive end expiratory pressure (cm $\left.\mathrm{H}_{2} \mathrm{O}\right)$; $\mathrm{OI}$ - oxygenation index $(-) ; \mathrm{PaO}_{2} / \mathrm{FiO}_{2}-$ hypoxemic index $(\mathrm{mm} \mathrm{Hg}) . P<$ values - comparison Time 4 vs. Time 1 . Data are expressed as median and interquartile range.

In group B $(n=20), 40 \%$ of patients were indicated for administration of inotropic support during the study. Based on the first hemodynamic evaluation, dobutamine was initiated in $15 \%$ of patients, and a further $25 \%$ of patients required additional inotropic therapy. Vasopressor therapy was indicated in $55 \%$ of patients, and concomitant treatment with dobutamine and noradrenaline was indicated in $15 \%$ of patients throughout the study. Only one patient with septic cardiomyopathy had an insufficient hemodynamic response to ionotropic treatment at time 2; however, the patient responded well to a combination of adrenaline and a phosphodiesterase III inhibitor, and subsequently to levosimendan monotherapy. Only one patient in this group needed phosphodiesterase III inhibitor monotherapy. From the point of view of pharmacological support, there were no statistical differences between the two groups. Children in group A required more inotropic support or combined inotropic and va- soactive therapy, although no significant difference was found. Children in group B were more often treated with vasoactive monotherapy.

In the first $48 \mathrm{~h}$ of the study, there was no significant difference in fluid intake between the two groups. During the course of the study, the fluid balance was normalized in both groups, but this change was more pronounced in group A. There was no significant difference in the total fluid balance between the two groups. This fact is clearly illustrated in Figure 1.

The ventilation parameters and indices are summarized in Table 3.

The results document a significant decrease in the peak inspiratory pressure (PIP) in group A during the study $(P<0.05)$, in addition to concomitant significant changes in the hypoxemic and oxygenation indices in the same group. No other differences were observed within group A during the study period. The analysis showed 
no significant differences within group B over the first 48 h. Comparisons between the groups showed significant differences over time with respect to peak inspiratory pressure (PIP; in Time $1 P<0.05$ and in Time $4 P<0.05$ ), mean airway pressure (Paw; in Time $1 P<0.001$ and in Time $4 P<0.05$ ), positive end expiratory pressure (PEEP; in Time $1 P<0.05$ and in Time $4 P<0.001)$, partial pressure of oxygen $\left(\mathrm{PaO}_{2}\right.$; in Time $1 P<0.05$ and in Time $\left.4 \mathrm{NS}\right)$, hypoxemic index $\left(\mathrm{PaO}_{2} / \mathrm{FiO}_{2}\right.$; in Time $1 \mathrm{NS}$ and in Time 4 NS ), and oxygenation index (OI; in Time $1 P<0.001$ and in Time $4 P<0.001)$, hypoxemic index $\left(\mathrm{PaO}_{2} / \mathrm{FiO}_{2}\right.$; in Time 10.001 and in Time 40.05 ) and lactate (Lactate; in Time 10.05 and in Time 4 NS).

\section{DISCUSSION}

The present prospective observational study included mechanically ventilated children admitted to the PICU. We focused on hemodynamic monitoring of the general PICU population and not patients with a uniform pathology; investigating hemodynamic changes within $48 \mathrm{~h}$ following initiation of mechanical ventilation (MV) and comparing the effect of MV on hemodynamics between patients with pulmonary and extra-pulmonary pathologies. The non-invasive ultrasound-based method, USCOM, was used in the present study, the accuracy of which has been validated, and the technique has been proven to be sufficiently sensitive to detect hemodynamic changes in both clinical and in vitro settings ${ }^{16,17}$. Several clinical studies in both adults and children have shown a positive impact of the treatment protocol on patient survival $^{18,19}$. Importantly, the first step in the hemodynamic management of critically ill patients is to determine the adequacy of tissue perfusion. Increasing cardiac output and oxygen delivery in patients with adequate organ perfusion serves no useful purpose, and targeting "supra-normal" hemodynamic parameters may even be harmful ${ }^{20}$. USCOM enables repeated evaluation of the main hemodynamic parameters, with the ability to obtain accurate hemodynamic data immediately upon presentation of a severe pathology offering new opportunities to rationalize therapy for individual patients ${ }^{21}$. USCOM has shown good intra- and inter-observer reliability in previously published studies $^{9}$.

The pathological condition was identified and the most appropriate medical support was selected based on hemodynamic assessment. Children ventilated for pulmonary pathology were characterized by a greater requirement for inotropic and combined inotropic/vasoactive therapy, which increased over the initial $48 \mathrm{~h}$ of ventilation; although there was no statistically significant difference between the two groups. The present study did not focus selectively on patients with bacterial infections, although infectious etiology was predominant in both groups. The pulmonary group included a majority of patients with bacterial pneumonia, and the non-pulmonary group included a substantial percentage of patients with bacterial sepsis and meningitis. The small percentage of patients in our sample with severe sepsis or septic shock can explain the differences in the hemodynamic profiles of our patients compared with those observed in previously published pediatric studies ${ }^{13,22-24}$.

Due to the higher inspiratory pressures used in children ventilated for lung pathology, more pronounced cardiopulmonary interactions can be expected ${ }^{25}$. Consistent with this assumption, patients with pulmonary pathology required higher inspiratory pressures to obtain the required tidal volume during $\mathrm{MV}$. Despite the lack of significant differences in hemodynamic profiles between the two groups, the requirement for inotropic or combined inotropic and vasopressor support in the pulmonary pathology group was more frequent.

A protective ventilation strategy was applied to both groups in the present study. The tidal volumes used in the pulmonary pathology group were consistent with those reported in pediatric studies of acute respiratory distress syndrome (ARDS) $\left(\right.$ ref. $\left.^{26,27}\right)$. Only a minority of patients from the pulmonary pathology group fulfilled the criteria for severe ARDS, for which low tidal volumes below 6 $\mathrm{mL} / \mathrm{kg}$ were used. However, the principle of a protective ventilation strategy was also applied to uninjured lungs (extra-pulmonary pathology), since several clinical and experimental studies have shown that the higher tidal volumes used for the mechanical ventilation of healthy lungs are associated with different adverse effects that may result in a ventilator-induced lung injury ${ }^{13,28,29}$. Analysis of arterial blood gases and ventilator indices within the same group revealed an improvement in these parameters over the initial $48 \mathrm{~h}$ of ventilation, which corresponds to pulmonary pathology resolution.

Importantly, the fluid requirements to reach the target hemodynamic parameters were equal in both groups studied in our cohort. Since a positive fluid balance has several negative impacts on critically ill children, the restriction and de-escalation of a positive fluid balance was reached in both groups on day 3 of the study. Two patients with pulmonary pathology needed extracorporeal renal replacement therapy. A negative fluid balance was reached in both groups on day 4 (data not shown). Fluid resuscitation and intravascular volume restoration typically represent the first-line treatments for circulatory failure in critically ill patients, and thus should be the first step in stabilizing circulation in patients with severe sepsis or septic shock ${ }^{14}$. The purpose of fluid resuscitation is to increase the preload and stroke volume in volumeresponsive patients. A number of dynamic tests of preload responsiveness have been developed in mechanically and spontaneously breathing patients ${ }^{30}$. If the fluid does not increase the cardiac output, then the volume load does not give the patient any benefit. There is evidence that a positive fluid balance in critically ill pediatric and adult patients is associated with several adverse effects. Analysis of an ARDS cohort demonstrates a clear correlation between the mean cumulative daily fluid balance and mortality in adults ${ }^{31}$. Similarly, further studies have shown increased morbidity associated with a positive fluid balance in critically ill patients ${ }^{32}$.

Commencement and dosing of, and withdrawal from, vasopressors, vasodilators, and inotropes in clinical prac- 
tice are still largely based on clinical assessment, and sometimes assisted via measurement of the surrogates of an inotrope such as ejection fraction, despite the wellknown shortcomings of these indices in critical care ${ }^{33}$. Hemodynamic monitoring plays an important role in the management of critically ill children, enabling the identification of pathophysiological changes and the choice of an appropriate treatment strategy.

\section{Study strengths and limitations}

The present study was conducted at a single tertiary pediatric center, and we acknowledge that a more diverse cohort of patients would improve the quality of our data. The study population is heterogeneous, including premorbidly healthy children and children with complex chronic defects such as congenital malformations or immunosuppression. The study groups are not comparable in number since most critically ill children in the PICU suffer from pulmonary pathology. Another limitation is the lack of anamnestic data on the duration of the pathological condition prior to admission; nevertheless, we may speculate as to what extent this may have influenced the hemodynamic patterns in our patients. To the best of our knowledge, however, there are no previous prospective observational studies evaluating the use of USCOM to describe the evolution of hemodynamic changes in the general population of critically ill children. With respect to the strengths of the present study, we underline its pragmatic perspective design and methodology.

\section{CONCLUSION}

The results of the present study support the following conclusions: (1) There was no statistically significant difference in the hemodynamic profiles between children ventilated for pulmonary and extra-pulmonary pathologies within 48 hours of initiation of MV; (2) Despite not achieving statistical significance, there was a trend toward more frequent inotropic and combined inotropic/vasopressor therapy in patients with pulmonary pathology, and the extra-pulmonary pathology group often required vasopressor therapy following initiation of MV; (3) A protective strategy for MV was associated with higher inspiratory pressures in the pulmonary pathology group, leading to more pronounced cardiopulmonary interactions as compared with the non-pulmonary pathology group; (4) Children in both groups required a comparable fluid intake to achieve hemodynamic goals; (5) The present data demonstrate that USCOM represents an easy-to-use noninvasive hemodynamic monitoring technique.

Acknowledgements: This study was supported by The Research Projects of Charles University in Prague, Czech Republic No. PRVOUK P36 and No. PROGRES Q39. Author contributions: JF: protocol development, USCOM monitoring, preliminary and final data analysis, and manuscript drafting; JK: protocol development, data analysis, and manuscript drafting and revision; KP, LS: data col- lection and analysis; JZ: data collection; JS: data analysis and manuscript drafting and revision.

Conflict of interest statement: The authors declare that they have no conflict of interest.

\section{REFERENCES}

1. Brierley J, Carcillo JA, Choong K, Cornell T, Decaen A, Deymann A, Doctor A, Davis A, Duff J, Dugas MA, Duncan A, Evans B, Feldman J, Felmet K, Fisher G, Frankel L, Jeffries H, Greenwald B, Gutierrez J, Hall M, Han YY, Hanson J, Hazelzet J, Hernan L, Kiff J, Kissoon N, Kon A, Irazuzta J, Lin J, Lorts A, Mariscalco M, Mehta R, Nadel S, Nguyen T, Nicholson C, Peters M, Okhuysen-Cawley R, Poulton T, Relves M, Rodriguez A, Rozenfeld R, Schnitzler E, Shanley T, Kache S, Skippen P, Torres A, von Dessauer B, Weingarten J, Yeh T, Zaritsky A, Stojadinovic B, Zimmerman J, Zuckerberg A. Clinical practice parameters for hemodynamic support of pediatric and neonatal septic shock: 2007 update from the American College of Critical Care Medicine. Crit Care Med 2009;37:666-88.

2. Gan H, Cannesson M, Chandler JR, Ansermino JM. Predicting fluid responsiveness in children: a systematic review. Anesth Analg 2013;117:1380-92.

3. Linton RA, Linton NW, Kelly F. Is clinical assessment of the circulation reliable in postoperative cardiac surgical patients? J Cardiothorac Vasc Anesth 2002;16:4-7.

4. Tibby SM, Hatherill M, Marsh MJ, Murdoch IA. Clinicians' abilities to estimate cardiac index in ventilated children and infants. Arch Dis Child 1997;7:516-18.

5. Deep A, Goonasekera CD, Wang Y, Brierley J. Evolution of hemodynamics and outcome of fluid-refractory septic shock in children. Intensive Care Med 2013;39:1602-9.

6. Weber T, Wagner T, Neumann K, Deusch E. Low predictability of three different noninvasive methods to determine fluid responsiveness in critically ill children. Pediatr Crit Care Med 2015;16:e89-94.

7. Cherpanath TG, Lagrand WK, Schultz MJ, Groeneveld AB. Cardiopulmonary interactions during mechanical ventilation in critically ill patients. Neth Heart J 2013;21:166-72.

8. Lansdorp $B$, Hofhuizen $C$, van Lavieren $M$, van Swieten $H$, Lemson $J$, van Putten MJ, van der Hoeven JG, Pickkers P. Mechanical ventilation-induced intrathoracic pressure distribution and heart-lung interactions. Crit Care Med 2017;42:1983-90.

9. Fan E, Needham DM, Stewart TE. Ventilatory management of acute lung injury and acute respiratory distress syndrome. JAMA 2005;294:2889-96.

10. Panico FF, Troster EJ, Oliveira CS, Faria A, Lucena M, João PR, Saad ED, Foronda FA, Delgado AF, de Carvalho WB. Risk factors for mortality and outcomes in pediatric acute lung injury/acute respiratory distress syndrome. Pediatr Crit Care Med 2015;16:194-200.

11. Kobr J, Třeška V, Moláček J, Kuntscher V, Liška V, Slavík Z. Comparison of Doppler flow Tei-indexes with pulmonary artery thermodilution measurement in an experimental porcine model. Physiol Res 2011;60:483-92.

12. Kobr J, Pizingerova K, Fremuth J, Sasek L, Fikrlova S, Jehlicka P, Slavik Z. Repeated bedside echocardiography in children with respiratory failure. J Cardiovasc Ultrasound 2011;9:14.

13. Fremuth J, Kobr J, Pizingerova K, Sasek L, Jehlicka P, Zamboryova J, Hess O, Vrzalova J, Racek J, Tonar Z. Healthy lung tissue response to mechanical ventilation in an experimental porcine model. In Vivo 2014;28:803-9.

14. Dellinger RP, Levy MM, Rhodes A, Annane D, Gerlach H, Opal SM, Sevransky JE, Sprung CL, Douglas IS, Jaeschke R, Osborn TM, Nunnally ME, Townsend SR, Reinhart K, Kleinpell RM, Angus DC, Deutschman CS, Machado FR, Rubenfeld GD, Webb SA, Beale RJ, Vincent JL, Moreno R, Surviving Sepsis Campaign Guidelines Committee including the Pediatric Subgroup. Surviving sepsis campaign: international guidelines for management of severe sepsis and septic shock: 2012. Crit Care Med 2013;41:580-637.

15. Report of the second task force on blood pressure control in children-1987. Task force on blood pressure control in children. National Heart, Lung, and Blood Institute, Bethesda, Maryland. Pediatrics 1987;79:1-25 
16. Gregory SD, Cooney H, Diab S, Anstey C, Thom O, Fraser JF. In vitro evaluation of an ultrasonic cardiac output monitoring (USCOM) device. J Clin Monit Comput 2016;30:69-75

17. O'Loughlin E, Ward M, Crossley A, Hughes R, Bremner AP, Corcoran T. Evaluation of the utility of the Vigileo FloTrac ${ }^{\mathrm{TM}}, \mathrm{LiDCO}^{\mathrm{TM}}, \mathrm{USCOM}$ and CardioQ $^{\mathrm{TM}}$ to detect hypovolemia in conscious volunteers: a proof of concept study. Anaesthesia 2015;70:142-49.

18. Rivers E, Nguyen B, Havstad S, Ressler J, Muzzin A, Knoblich B, Peterson E, Tomlanovich M. Early Goal-Directed Therapy Collaborative Group. Early goal-directed therapy in the treatment of severe sepsis and septic shock. N Engl J Med 2001;345:1368-77.

19. de Olivera CF, de Oliveira DS, Gottschald AF, Moura JD, Costa GA Ventura AC, Fernandes JC, Vaz FA, Carcillo JA, Rivers EP, Troster EJ. ACCM/PALS haemodynamic support guidelines for pediatric septic shock: an outcomes comparison with and without monitoring central venous oxygen saturation. Intensive Care Med 2008;34:1065-75

20. Caile V, Squara P. Oxygen uptake-to-delivery relationship: a way to assess adequate flow. Crit Care 2006;10(SUPPL 3):S4.

21. Turnham $\mathrm{H}$, Brierley J. New methods of monitoring shock in children. Curr Treat Options Pediatr 2015;1:15-24.

22. Dhanani S1, Barrowman NJ, Ward RE, Murto KT. Intra- and interobserver reliability using a noninvasive ultrasound cardiac output monitor in healthy anesthetized children. Paediatr Anaesth 2011;21:858-64.

23. Deep A, Goonasekera CD, Wang Y, Brierley J. Evolution of hemodynamics and outcome of fluid-refractory septic shock in children. Intensive Care Med 2013;39:1602-9.

24. Brierley J, Peters MJ. Distinct hemodynamic patterns of septic shock at presentation to pediatric intensive care. Pediatrics 2008;122:752 59.

25. Bronicki RA, Anas NG. Cardiopulmonary interaction. Pediatr Crit Care Med 2009;10:313-22.
26. Erickson S, Schibler A, Numa A, Nuthall G, Yung M, Pascoe E, Wilkins B. Acute lung injury in pediatric intensive care in Australia and New Zealand: a prospective, multicenter, observational study. Pediatr Crit Care Med 2007:8:317-23.

27. Santschi M, Jouvet P, Leclerc F, Gauvin F, Newth CJ, Carroll CL, Flori H, Tasker RC, Rimensberger PC, Randolph AG on behalf of the PALIVE Investigators; Pediatric Acute Lung Injury and Sepsis Investigators Network (PALISI) and the European Society of Pediatric and Neonatal Intensive Care (ESPNIC). Acute lung injury in children: therapeutic practice and feasibility of international clinical trials. Pediatr Crit Care Med 2010;11:681-9.

28. Sutherasan $Y$, Vargas M, Pelosi P. Protective mechanical ventilation in the non-injured lung: review and meta-analysis. Crit Care 2014;18:211.

29. Kobr J, Topolcan O, Kuntscher V, Molacek J, Piyingerova K, Kocova $J$, Hes O. Diffuse alveolar damage due to inappropriate strategy of mechanical ventilation in an experimental porcine model. In Vivo 2010;24:699-704

30. Guerin L, Monnet X, Teboul JL. Monitoring volume and fluid responsiveness: from static to dynamic indicators. Best Pract Res Clin Anaesthesiol 2013;27:177-85.

31. Rosenberg AL, Dechert RE, Park PK, Bartlett RH; NIH NHLBI ARDS Network. Review of a large clinical series: association of cumulative fluid balance on outcome in acute lung injury: a retrospective review of the ARDS net tidal volume study cohort. J Intensive Care Med 2009;24:35-46.

32. Sinitsky L, Walls D, Nadel S, Inwald DP. Fluid overload at 48 hours is associated with respiratory morbidity but not mortality in a general PICU: retrospective cohort study. Pediatr Crit Care Med 2015;16:2059.

33. Smith BE, Madigan VM. Non-invasive method for rapid bedside estimation of inotropy: theory and preliminary clinical validation. $\mathrm{Br} J$ Anaesth 2013;111:580-88. 